\title{
Prenatal Diagnosis of Persistent Left Superior Vena Cava and its Clinical Significance
}

\author{
Aytül Çorbacioğlu Esmer ${ }^{1}$, Atıl Yüksel ${ }^{1}$, Halime Çal1 ${ }^{1}$, Mehmet Özsürmeli $^{1}$, Rukiye Eker Ömeroğlu ${ }^{2}$, \\ İbrahim Kalelioğlu ${ }^{1}$, Recep Has ${ }^{1}$
}

${ }^{1}$ Department of Obstetrics and Gynecology, İstanbul University Faculty of Medicine, İstanbul, Turkey

${ }^{2}$ Department of Pediatric Cardiology, İstanbul University Faculty of Medicine, İstanbul, Turkey

Background: Persistent left superior vena cava (PLSVC) is a variant of systemic venous return which is observed in $0.3 \%$ of autopsies in the general population and in 4-8\% of patients with congenital heart disease. Aims: To evaluate associated cardiac, extracardiac and chromosomal anomalies in prenatally diagnosed cases of PLSVC and to review their outcome.

Study Design: Retrospective comparative study.

Methods: The data of patients with a prenatal diagnosis of PLSVC between May 2008 and January 2013 were reviewed retrospectively. Results: Data of 31 cases were reviewed. Fifteen (48.4\%) cases were associated with cardiac defects and 17 (54.8\%) cases had associated extracardiac sonographic or postpartum findings. Two fetuses had karyotype anomalies. Outcome was significantly more favorable in cases not associated with cardiac defects in comparison to those as- sociated with cardiac anomalies $(84.6 \%$ vs. $33.3 \%, \mathrm{p}=0.009)$. All cases with isolated PLSVC survived, while among the cases associated with extracardiac anomalies, with cardiac anomalies and with both extracardiac and cardiac anomalies, the survival rate was $75 \%, 50 \%$ and $22.2 \%$, respectively. The most frequent group of cardiac anomalies associated with PLSVC was septal defects and VSD was the most common heart defect individually, being observed in nine fetuses.

Conclusion: Prenatally diagnosed PLSVC is associated with cardiac and extracardiac anomalies in the majority of cases. Outcome is significantly worse if PLSVC is associated with a cardiac defect, and the prognosis is excellent in isolated cases.

(Balkan Med J 2014;31:50-54).

Key Words: Cardiac anomaly, congenital anomaly, persistent left superior vena cava, prenatal diagnosis, ultrasound
Persistent left superior vena cava (PLSVC) is a variant of systemic venous return which is observed in $0.3 \%$ of autopsies in the general population and in $4-8 \%$ of patients with congenital heart disease (1). In the embryonic period, the right and left anterior cardinal veins constitute the main venous drainage of the cephalic portion, and as a result of the development of the left innominate vein that bridges the anterior cardinal veins at 8 weeks gestation, the proximal part of the left cardinal vein regresses and only a small portion of it remains as the left superior intercostal vein (LSVC) (2-4). A defect in the regression of this vein is thought to be the cause of the persistence of the LSVC. PLSVC drains mostly into the right atrium via the coronary sinus, and into the left atrium in $10 \%$ of cases (4). In general, the diagnosis of PLSVC has no clinical impact, because it is asymptomatic, and the systemic venous blood continues to return to the right atrium $(5,6)$. However, a prenatal diagnosis of PLSVC plays an important role in prenatal counseling and management, since it is associated with cardiac and extra-cardiac diseases with an incidence as high as $83 \%$ and $48 \%$, respectively $(2,6)$.
There are only a few series of prenatally diagnosed PLSVC in the literature $(2,6,7)$. In this study, we aimed to identify prenatally diagnosed cases of PLSVC in our clinic, to evaluate the associated cardiac, extracardiac and chromosomal anomalies, and to review their outcome.

\section{MATERIAL AND METHODS}

In this study, the data of patients with prenatal diagnosis of PLSVC between May 2008 and January 2013 were reviewed retrospectively. All patients were examined in a tertiary referral center for prenatal diagnosis where an anatomic survey and fetal echocardiography were performed in a standardized fashion with high resolution equipment (Voluson 730 Expert, GE Healthcare, Milwaukee, WI, USA and Xario SSA-660A, Toshiba Medical Systems). Fetal echocardiography was carried out by visualizing standard anatomical planes including the observation of the situs, the position of the heart, the four-chamber view, the outflow tracts, the three-vessel view, the aortic and ductal arches and both systemic and pulmonary venous 
returns, and incorporating pulsed-wave and color Doppler imaging. PLSVC was diagnosed when the three-vessel view was abnormal with a supernumerary vessel located to the left of the pulmonary trunk and arterial duct (Figure 1). All cases were examined by a perinatologist and a pediatric cardiologist, and all parents were counseled based on the cardiac and extracardiac pathologic findings associated with PLSVC. An invasive prenatal procedure for karyotype analysis was offered in the presence of standard indications such as advanced maternal age, family history of aneuploidy, increased risk on the first or second trimester screening test for Down syndrome and the presence of malformations on ultrasound. Fluorescence in situ hybridization (FISH) study for the 22q11 deletion was also recommended when a conotruncal anomaly was detected on ultrasound. For the cases without prenatal karyotyping, chromosome analysis was performed postnatally according to clinical findings.

This study was approved by the Institutional Ethics Committee of İstanbul Faculty of Medicine. Informed consent was obtained from all participants. The clinical data retrieved from hospital records, ultrasound reports and prenatal diagnosis databases include maternal age, gestational age at diagnosis, fetal gender, sonographic cardiac and extracardiac findings, genetic analysis, and outcome of pregnancy. The conditions associated with heterotaxy such as malposition of the abdominal viscera were not taken into account as extracardiac malformations. If prenatal or postnatal chromosome analysis was not performed, the karyotype was considered to be normal in healthy infants with no clinical findings. Prenatal diagnosis was confirmed by postnatal echocardiography or cardiac surgery in all surviving patients, and by autopsy in case of termination of pregnancy (TOP) or in utero death, except for the cases in which parents did not accept postmortem examination. For the five patients who did not attend to our hospital for postnatal examination, data regarding outcome was obtained by contacting the parents by telephone. The outcome was considered favorable if the infant was alive and doing well, while TOP, in utero death and neonatal death constituted unfavorable outcomes. Statistical analysis was performed using Fisher's exact test and the Mann-Whitney $U$ test. All values are given as mean \pm SD. $\mathrm{p}<0.05$ was considered to be significant.

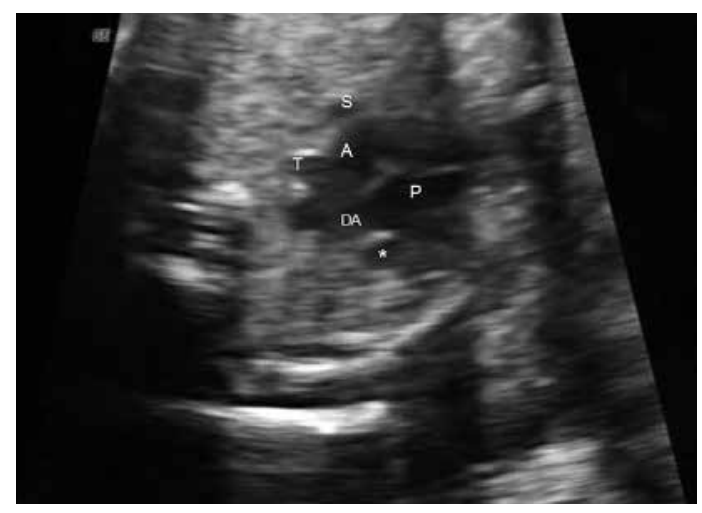

FIG. 1. Three-vessel-trachea view. Asterisk shows the persistent left superior vena cava located left of the pulmonary artery and ductal arch. (P: pulmonary artery; DA: ductal arch; A: aorta; T: trachea; S: superior vena cava)

\section{RESULTS}

Over the study period, a total of 35 fetuses with PLSVC were examined. Four of them were excluded due to incomplete data and loss to follow up. In all of the 31 cases, a normal right superior vena cava (RSVC) was also present. Seven cases were referred to our center with a suspicion of PLSVC. Fourteen cases were referred due to other cardiac and extracardiac defects, and PLSVC was detected during echocardiography. In 10 cases, PLSVC was detected in our clinic during routine ultrasound scanning. The demographic characteristics, associated extracardiac findings, karyotype and outcome of the fetuses are shown in Table 1. The cases were categorized into two groups: Group 1 constituted cases without associated sonographic or postnatal cardiac defects, while group 2 included those with associated sonographic and/or postnatal cardiac defects. Group 1 included $16(51.6 \%)$ fetuses, and in half of them additional extracardiac findings were observed. Thirteen $(81.25 \%)$ fetuses had a normal karyotype. In a case with choroid plexus cyst and thickened nuchal fold, trisomy 21 was diagnosed postnatally, because the parents did not accept an invasive procedure during pregnancy. Group 2 involved $15(48.4 \%)$ fetuses and in $9(60 \%)$ of them additional extracardiac findings were observed. Eleven $(73.3 \%)$ fetuses had a normal karyotype, and one fetus with overlapping fingers, fetal growth restriction, choroid plexus cyst, double outlet right ventricle, ventricular septal defect (VSD) and aberrant right subclavian artery was found to have a $47, \mathrm{XX}+18$ karyotype. The rate of aneuploidy in the total cohort was $7.7 \%(2 / 26)$.

The cases were followed up for a period of 3 months to 6 years. The outcome was significantly more favorable in Group 1 in comparison to Group 2 (84.6\% vs. 33.3\%, p=0.009) (Table 1). Table 2 shows the outcome of cases (except for the unborn fetuses) in detail. All cases with isolated PLSVC survived and were doing well at the time of writing. On the other hand, among the cases associated with extracardiac defects, with other cardiac defects and with both extracardiac and cardiac defects, the survival rate was $75 \%, 50 \%$ and $22.2 \%$, respectively. Eight cases were operated on for extracardiac defects or cardiac defects other than PLSVC, and three of them died postoperatively. Five of them were good in health at the time of writing. The features of all cases in Group 1 and Group 2 are summarized in Table 3 and Table 4, respectively.

The most frequent group of cardiac anomalies was septal defects (eleven cases) followed by conotruncal anomalies (four cases), left ventricular outflow obstructive diseases (four cases) and heterotaxy syndromes (three cases). VSD was the most common heart defect individually and was observed in nine fetuses.

\section{DISCUSSION}

In this study, we reviewed the prenatal and postnatal cardiac and extracardiac findings, associated chromosomal anomalies and outcome in 31 PLSVC cases. Prenatally, PLSVC is easily and accurately diagnosed in the three-vessel view, where four vessels are visualized instead of three, with an extra vessel lo- 
cated to the left of the pulmonary trunk (3). In rare instances of the absence of the RSVC, there are three abnormally arranged vessels aligned, i.e. the aorta, pulmonary artery and PLSVC from right to left. Significant dilatation of the coronary sinus (Figure 2), which is best visualized in a transverse transthoracic cross-sectional plane slightly caudal to the apical four-cham-

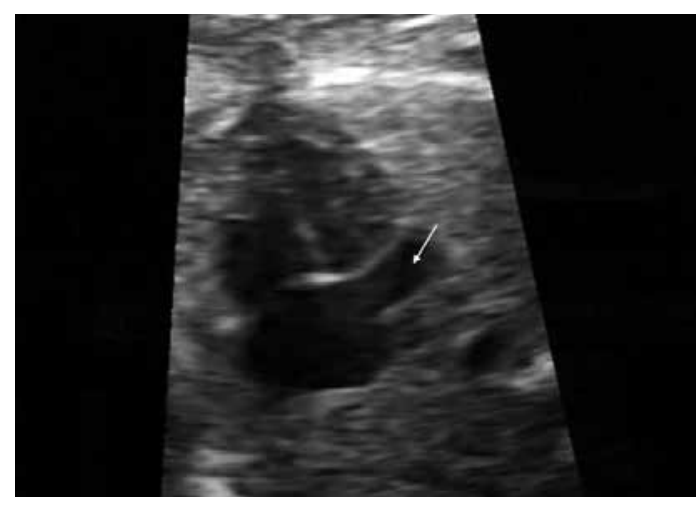

FIG. 2. Transverse view of the fetal chest in a plane slightly caudal to the apical four-chamber view showing a dilated coronary sinus (arrow)

TABLE 1. Demographic and clinical characteristics of cases. (Group 1: cases not associated with cardiac defects, Group 2: cases associated with cardiac defects).

\begin{tabular}{lccc}
\hline & $\begin{array}{c}\text { Group 1 } \\
(\mathrm{n}=16)\end{array}$ & $\begin{array}{c}\text { Group 2 } \\
(\mathrm{n}=15)\end{array}$ & $\begin{array}{c}\text { Total }(\%) \\
(\mathrm{n}=31)\end{array}$ \\
\hline Age $($ mean \pm SD, year)* & $30.1 \pm 3.5$ & $29.5 \pm 6.1$ & $29.8 \pm 4.9$ \\
GAD (mean \pm SD, week)* & $24.1 \pm 4$ & $25 \pm 5.2$ & $24.5 \pm 4.6$ \\
Fetal gender* & $(\mathrm{n}=13)$ & $(\mathrm{n}=15)$ & $(\mathrm{n}=28)$ \\
$\quad$ Male & $7(53.8)$ & $10(66.6)$ & $17(60.8)$ \\
Female & $6(46.2)$ & $5(33.3)$ & $11(39.2)$ \\
Extracardiac anomalies* & $8(50)$ & $9(60)$ & $17(54.8)$ \\
Karyotype* $^{*}$ & $(\mathrm{n}=14)$ & $(\mathrm{n}=12)$ & $(\mathrm{n}=26)$ \\
$\quad$ Normal & $13(92.8)$ & $11(91.7)$ & $24(92.3)$ \\
Aneuploidy & $1(7.2)$ & $1(8.3)$ & $2(7.7)$ \\
Outcome & $(\mathrm{n}=13)$ & $(\mathrm{n}=15)$ & $(\mathrm{n}=28)$ \\
$\quad$ Favorable & $11(84.6)$ & $5(33.3)$ & $16(57.2)$ \\
$\quad$ Unfavorable & $2(15.4)$ & $10(66.6)$ & $12(42.8)$ \\
\hline
\end{tabular}

GAD: gestational age at diagnosis

(Unfavorable outcome includes neonatal death, termination of pregnancy and in utero death)

*Group 1 vs. Group 2 is insignificant $(\mathrm{p}>0.05)$

Group 1 vs. Group 2 is significant ( $\mathrm{p}=0.009$ ) ber view, is an indirect sign of PLSVC, as well (8). However, the presence of PLSVC must be confirmed in the three-vessel view, because anomalous pulmonary venous drainage may also cause significant dilatation of the coronary sinus (8). Also, a dilated coronary sinus may be misdiagnosed as an ostium primum atrial septal defect at the level of the opening of the coronary sinus into the right atrium or as mitral atresia since the mitral valve is pushed anteriorly by the coronary sinus and may not be seen in the four-chamber view (7).

The most significant clinical implication of prenatally diagnosed PLSVC is the association with cardiac and extracardiac defects. Previously, Galindo et al. (6) reported that 44 of 54 cases $(81.4 \%)$ with PLSVC were associated with a cardiac defect; the corresponding rate in the series of Berg et al. (2) was $83 \%(68 / 82)$. Unlike these results, more than half $(16 / 31)$ of the cases in our series were not associated with additional cardiac malformation. Furthermore, seven cases $(9 \%)$ in the series of Berg et al. (2) and three cases (5.5\%) in the series of Galindo et al. (6). had isolated PLSVC with no associated cardiac or extracardiac findings, in contrast to our series in which the corresponding rate was as high as $25.8 \%(8 / 31)$. The inconsistency of our findings with the previous studies may be a result of more common incorporation of three-vessel view in routine systematic ultrasound examination of fetal heart in the last few years, since these previous series were published in 2006 and 2007.

Nsah et al. (9) postulated that for the regression of the left anterior cardinal vein, compression by the growing lungs and the increasing size of the atria are necessary. In their postnatal series, a significantly more frequent association was recorded with anomalies, such as atrioventricular canal malformation, mitral atresia and cor triatratum, which reduce compression of the developing LSVC (9). On the other hand, PLSVC is present in $50-70 \%$ of the cases with heterotaxy, suggesting that the presence of PLSVC is more likely to be associated with the underlying defect of lateralization rather than mechanical factors (2). In our series, septal defects were the most common cardiac defect, followed by left outflow tract obstruction and conotruncal anomalies. Heterotaxy was observed in only 3 of the 15 cases with cardiac defects being much lower than the other previous prenatal series in which it was reported as $41-54 \%(2,6)$. Atrioventricular septal defects, right outflow tract obstruction and double outlet right ventricle were the most common cardiac anomalies in the cases with heterotaxy in previous series, while the spectrum of cardiac malformations differed in the

TABLE 2. Outcome of the cases (except for unborn fetuses)

\begin{tabular}{lccccc}
\hline & $\begin{array}{c}\text { Isolated PLSVC } \\
(\mathrm{n}=5)\end{array}$ & $\begin{array}{c}\text { PLSVC and } \\
\text { extracardiac defects } \\
(\mathrm{n}=8)\end{array}$ & $\begin{array}{c}\text { PLSVC and other } \\
\text { cardiac defects } \\
(\mathrm{n}=6)\end{array}$ & $\begin{array}{c}\text { PLSVC plus both cardiac } \\
\text { and extracardiac defect findings } \\
(\mathrm{n}=9)\end{array}$ & $\begin{array}{c}\text { Total } \\
(\mathrm{n}=28)\end{array}$ \\
\hline Well & $5(100 \%)$ & $6(75 \%)$ & $3(50 \%)$ & $4(22.2 \%)$ & $16(57.1 \%)$ \\
NND & - & - & $3(50 \%)$ & $2(22.2 \%)$ & $7(25 \%)$ \\
TOP & - & $2(25 \%)$ & - & $1(11.1 \%)$ & $4(14.3 \%)$ \\
IUD & - & - & - & & $1(3.6 \%)$ \\
\hline
\end{tabular}

PLSVC: persistent left superior vena cava; NND: neonatal death; TOP: termination of pregnancy; IUD: in utero death 
TABLE 3. Features of cases not associated with cardiac defects

\begin{tabular}{|c|c|c|c|c|c|c|}
\hline & Age (year) & GAD (week) & Gender & Extracardiac findings & Karyotype & Outcome, age \\
\hline 1 & 30 & 26 & Male & None & Normal & Survived, 6 months \\
\hline 2 & 30 & 26 & Female & None & Normal & Survived, 2 years \\
\hline 3 & 31 & 19 & Male & None & Normal & Survived, 2 years \\
\hline 4 & 33 & 22 & Male & Cloacal malformation, unilateral MDK & Normal & TOP \\
\hline 5 & 25 & 24 & Male & CPC, nuchal edema & Trisomy 21 & Survived, 2 years \\
\hline 6 & 29 & 18 & Male & $\begin{array}{l}\text { Borderline ventriculomegaly, interhemispheric cyst, cleft } \\
\text { lip-palate, bilateral PEV }\end{array}$ & Normal & TOP \\
\hline 7 & 33 & 23 & Female & $\mathrm{CPC}$ & Normal & Survived, 4 years \\
\hline 8 & 26 & 28 & Female & FGR & Normal & Survived, 5 years \\
\hline 9 & 34 & 30 & Female & None & Normal & Survived, 3 years \\
\hline 10 & 31 & 33 & Male & $\begin{array}{l}\text { Polyhydramnios, anal atresia, esophagus atresia, unilateral } \\
\text { hypoplastic kidney }\end{array}$ & Normal & Surgery, survived, 6 years \\
\hline 11 & 31 & 24 & Female & None & Normal & Survived, 3 months \\
\hline 12 & 35 & 24 & Female & None & Normal & Survived, 6 years \\
\hline 13 & 29 & 23 & Male & FGR, ductus venosus agenesis, polyhydramnios & Normal & Survived, 2.5 years \\
\hline 14 & 24 & 22 & Unknown & None & Not performed & Not born \\
\hline 15 & 26 & 24 & Unknown & SUA & Normal & Not born \\
\hline 16 & 36 & 19 & Unknown & None & Not performed & Not born \\
\hline
\end{tabular}

GAD: gestational age at diagnosis; MDK: multicystic dysplastic kidney; TOP: termination of pregnancy; CPC: choroid plexus cyst

PEV: per equinovarus; FGR: fetal growth restriction; SUA: single umbilical artery

TABLE 4. Features of cases associated with cardiac defects

\begin{tabular}{|c|c|c|c|c|c|c|c|}
\hline & $\begin{array}{c}\text { Age } \\
\text { (year) }\end{array}$ & $\begin{array}{c}\text { GAD } \\
\text { (week) }\end{array}$ & Gender & Cardiac findings & Extracardiac findings & Karyotype & Outcome, age \\
\hline 1 & 27 & 22 & Male & APW, TOF & Hemivertebra, unilateral agenesis of ribs & Normal & TOP \\
\hline 2 & 36 & 20 & Female & DORV, ARSA, VSD & CPC, overlapping fingers, FGR & Trisomy 18 & NND \\
\hline 3 & 24 & 29 & Male & $\begin{array}{l}\text { AVSD, TGA, pulmonary atresia, } \\
\text { right isomerism }\end{array}$ & Oligohydramnios, FGR & Normal & Survived, NND \\
\hline 4 & 27 & 35 & Male & $\begin{array}{l}\text { Single ventricle, ASD, VSD, } \\
\text { interrupted IVC }\end{array}$ & None & Not performed & NND \\
\hline 6 & 35 & 23 & Female & HLV, aortic stenosis & None & Normal & Surgery, NND \\
\hline 7 & 20 & 30 & Male & $\begin{array}{l}\text { HRV, tricuspid atresia, left isomerism, } \\
\text { VSD, ASD, TGA }\end{array}$ & None & Normal & Surgery, survived, 1.5 years \\
\hline 8 & 32 & 20 & Male & Malalignment VSD & None & Normal & Surgery, survived, 1 year \\
\hline 9 & 27 & 22 & Female & Malalignment VSD & None & Normal & Surgery, survived, 3 years \\
\hline 10 & 30 & 24 & Male & $\mathrm{CoA}$ & SUA, ductus venosus agenesis & Normal & NND \\
\hline 14 & 21 & 21 & Male & $\begin{array}{l}\text { VSD, non-compaction, dysplastic tricuspid } \\
\text { valve, TR, cardiomegaly }\end{array}$ & PEV, hyperechogenic bowel & Not performed & IUD \\
\hline 15 & 24 & 22 & Male & AVSD, right aortic arch & $\begin{array}{l}\text { Partial vermian agenesis, cleft lip-palate, } \\
\text { micropenis, polyhydramnios }\end{array}$ & Not performed & TOP \\
\hline
\end{tabular}

other cases $(2,6)$. The most frequent anomalies were reported to be VSD and coarctation of the aorta in the study by Berg et al. (2), and left outflow tract obstructive diseases and conotruncal anomalies in the study by Galindo et al. (6).
The association of PLSVC with chromosomal anomalies was previously reported in the literature $(4,7)$. The rate of aneuploidy was $7.7 \%$ in our series, similar to the series of Berg et al. (2) and Galino et al. (6) in which the corresponding rate 
was reported to be $9 \%$ in each. Kalache et al. (4) recommended karyotype analysis when the diagnosis of PLSVC with a dilated coronary sinus was made, based on the possibility of missing some cardiac anomalies and obscure extracardiac anomalies suggesting aneuploidy. The case reported by Kalache et al. (4), as well as 12 fetuses with aneuploidy in the series of Berg et al. (2) and Galindo et al.,(6) had additional prenatal sonographic cardiac findings. Therefore, it was suggested that cardiac defects themselves, but not PLSVC, were associated with an abnormal karyotype $(2,6)$. On the other hand, chromosomal anomalies were present in five of the 15 fetuses with no additional cardiac defects in a recently published study by Barea et al. (7). Moreover, one of these cases in which neonatal karyotyping revealed trisomy 21 had no associated extracardiac defect (7). In our series, there were two aneuploidy cases. In the case with trisomy 18 , there were multiple cardiac and extracardiac anomalies which caused the suspicion of a chromosomal anomaly. In the other case with trisomy 21 , a choroid plexus cyst and thickened nuchal fold in the second trimester were clues suggesting the presence of chromosomal anomaly. Nevertheless, the number of cases reported in the literature is not enough to draw the conclusion that PLSVC should be accepted as a marker for trisomy 21.

The outcome of PLSVC is associated with the other cardiac and extracardiac findings. In previous studies, all of the isolated cases had a favorable prognosis, in contrast to the high neonatal mortality and TOP rates in those associated with cardiac defects. Similarly, in our cohort, all fetuses with isolated PLSVC did well after birth, while the survival rate declined to $50 \%$ when an additional cardiac anomaly was observed, and to $22.2 \%$ when an extracardiac finding was also present. These findings support the suggestion that isolated PLSVC is a benign anomaly which should prompt a meticulous examination of the fetus to identify additional cardiac and extracardiac anomalies.

In contrast to the prenatal diagnosis, the detection of PLS$\mathrm{VC}$ is difficult postnatally in routine transthoracic echocardiographic studies (6). Usually, a normal RSVC is present in addition to PLSVC, as with all cases in our series. PLSVC has no hemodynamic effects and does not need treatment; however, in rare cases with no RSVC, the diagnosis has significant clinical implications in adulthood. Firstly, this situation may cause difficulties in interventions, such as implantation of a transvenous pacemaker, systemic venous cannulation for cardiopulmonary bypass and placement of a pulmonary artery catheter for intraoperative or intensive care unit monitoring $(10,11)$. Secondly, it may cause dysrhythmias in adulthood due to the deformation of conduction pathways secondary to coronary sinus dilatation. Prenatal diagnosis of the absence of the RSVC may allow monitoring of coronary sinus dimensions and help to identify dysrhythmias using echocardiography and Holter recording, as was recommended by Guarnieri et al. (11).

This study had some limitations such as its retrospective nature. Also, our study group involved a selected population that was referred to a tertiary center, and this might have led to biased results. Furthermore, not all of the patients underwent karyotyping, and the karyotypes of a few cases remain unknown. However, despite these limitations, with this study we underline the significance of the three-vessel view during routine fetal screening and draw attention to the increasing incidence of isolated PLSVC cases in clinical practice.

In conclusion, PLSVC is a vascular variation which is associated with cardiac and extracardiac anomalies in the majority of cases. The outcome is significantly worse if PLSVC is associated with a cardiac defect, but the prognosis is excellent in isolated cases. Prenatal diagnosis of PLSVC is significant, because it paves the way for the diagnosis of structural and chromosomal anomalies as it leads the physician to perform fetal echocardiography and a detailed anatomic survey.

Ethics Committee Approval: Ethics committee approval was received for this study from the ethics committee of İstanbul Faculty of Medicine.

Informed Consent: Written informed consent was obtained from patients who participated in this study.

\section{Peer-review: Externally peer-reviewed.}

Author contributions: Concept - A.Ç.E., R.E., İ.K.; Design - A.Ç.E., A.Y., R.E.; Supervision - A.Y., R.H.; Resource - I.K., R.E.; Materials - A.Ç.E., H.Ç., M.Ö.; Data Collection\&/or Processing - H.Ç., M.Ö., R.E.; Analysis\&/or Interpretation - A.Ç.E., İ.K.; Literature Search - A.Ç.E.; Writing - A.Ç.E.; Critical Reviews - A.Y., R.H.

Conflict of Interest: No conflict of interest was declared by the authors.

Financial Disclosure: The authors declared that this study has received no financial support.

\section{REFERENCES}

1. Jouannic JM, Picone O, Martinovic J, Fermont L, Dumez Y, Bonnet D. Diminutive fetal left ventricle at mid-gastation associated with persistent left superior vena cava and coronary sinus dilatation. Ultrasound Obstet Gynecol 2003;22:527-30. [CrossRef]

2. Berg C, Knüppel M, Geipel A, Kohl T, Krapp M, Knöpfle G, et al. Prenatal diagnosis of persistent left superior vena cava and its associated congenital anomalies. Ultrasound Obstet Gynecol 2006;27:274-80. [CrossRef]

3. Pasquini L, Belmar C, Seale A, Gardiner HM. Prenatal diagnosis of absent right and persistent left superior vena cava. Prenat Diagn 2006;26:700-2. [CrossRef]

4. Kalache KD, Romero R, Conoscenti G, Qureshi F, Jacques SM, Chaiworapongsa T, et al. Prenatal diagnosis of dilated coronary sinus with persistent left superior vena cava in a fetus with trisomy 18. Prenat Diagn 2003;23:108-10. [CrossRef]

5. Thompson C. Congenital cardiac malformations in relation to central venous access. Br J Nurs 2006;15:276-81.

6. Galindo A, Gutierrez-Larraya F, Escribano D, Arbues J, Velasco JM. Clinical significance of persistent left superior vena cava diagnosed in fetal life. Ultrasound Obstet Gynecol 2007;30:152-61. [CrossRef]

7. Barea C, Ovaert C, Moniotte S, Biard J-M, Steenhaut P, Bernard P. Prenatal diagnosis of abnormal cardinal systemic venous return without other heart defects: a case series. Prenat Diagn 2011;31:380-8. [CrossRef]

8. Chaoui R, Heling KS, Kalache KD. Caliber of the coronary sinus in fetuses with cardiac defects with and without left persistent superior vena cava and in growth-restricted fetuses with heart-sparing effect. Prenat Diagn 2003;23:552-7. [CrossRef]

9. Nsah EN, Moore GW, Hutchins GM. Pathogenesis of persistent left superior vena cava with a coronary sinus connection. Pediatr Pathol 1991;11:261-9. [CrossRef]

10. Freund M, Stoutenbeek P, ter Heide H, Pistorius L. 'Tobacco pipe' sign in the fetus: patent left superior vena cava with absent right superior vena cava. Ulrasound Obstet Gynecol 2008;32:592-7. [CrossRef]

11. Guarnieri GF, Romano F, Cleico L, Balducci G. Absent right and persistent keft superior vena cava: Fetal and neonatal echocardiographic diagnosis. Pediatr Cardiol 2006;27:646-8. [CrossRef] 